\title{
Study on Physical Properties of Exotic and Indigenous breed Eggs
}

\author{
N. Sumashree ${ }^{1 *}$, Sharanagouda Hiregoudar ${ }^{1}$, Udaykumar Nidoni ${ }^{1}$, \\ K.T. Ramappa ${ }^{1}$, Nagaraj Naik ${ }^{2}$ and G.D. Vasanth Kumar ${ }^{1}$ \\ ${ }^{1}$ Department of Processing and Food Engineering, College of Agricultural Engineering, \\ University of Agricultural Sciences, Raichur- 584 101, Karnataka, India \\ ${ }^{2}$ Department of Agricultural Microbiology, College of Agriculture, University of Agricultural \\ Sciences, Raichur- 584 101, Karnataka, India
}

\section{A B S T R A C T}

\begin{tabular}{|c|}
\hline Keywords \\
\hline $\begin{array}{l}\text { Exotic breed eggs, } \\
\text { Indigenous breed } \\
\text { eggs, External and } \\
\text { internal properties }\end{array}$ \\
\hline Article Info \\
\hline $\begin{array}{l}\text { Accepted: } \\
\text { 04 August } 2019 \\
\text { Available Online: } \\
10 \text { September } 2019\end{array}$ \\
\hline
\end{tabular}

The present investigation was aimed to evaluate the physical properties of exotic and indigenous breed eggs. The collected eggs were analyzed for external and internal qualities. A significant difference $\left(\mathrm{t}_{\mathrm{cal}}>\mathrm{t}_{\mathrm{tab}}\right)$ was recorded in quality parameters like weight $(55.82$ and $43.66 \mathrm{~g})$, surface area $\left(67.35\right.$ and $\left.57.29 \mathrm{~cm}^{2}\right)$, volume $\left(50.96\right.$ and $\left.39.86 \mathrm{~cm}^{3}\right)$, albumen width $(6.43$ and $5.89 \mathrm{~mm})$, albumen height $(7.56$ and $5.32 \mathrm{~mm})$, yolk height (16.55 and $14.76 \mathrm{~mm}$ ), albumen weight (34.17 and $24.46 \mathrm{~g})$, yolk weight (15.64 and 13.95 g), albumen ratio (61.23 and 56.02), yolk diameter (4.29 and $3.84 \mathrm{~mm}$ ) and yolk: albumen ratio (45.78 and 57.14)of exotic and indigenous breed eggs. It was observed that exotic breed eggs had a superior external and internal quality features when compared with indigenous breed eggs. However, the quality traits such as length, width, shape index, shell weight, shell thickness, shell ratio, albumen length, yolk length, yolk width, albumen index, yolk index, yolk ratio and Haugh unit have no much variation comparatively. Hence, on overall basis, the present study concludes that exotic breed eggs are considered for commercial usage.

\section{Introduction}

Chicken egg is considered as one of the most nutritious food that can be consumed alone or as a food ingredient (Ahmadi et al., 2016). As a source of human food, egg provides a wide range of nutrients including proteins, minerals and vitamins. Egg production varies throughout the year. The worldwide egg production has been increased continuously up to 74 tonnes in 2018 (FAOSTAT, 2018). It is reported that, India is the third largest egg producer in the world with the physical target of total production 10.17 billion eggs and Karnataka about 556.6 million eggs per year (Indiastat, 2019). Many factors are attributed to these variations such as age, breed, feed, climate and body weight (Mutayoba et al., 2011). As far as egg consumption is concerned, egg quality is the characteristics of an egg that affect its acceptability to the consumer (Stadelman, 1995). Hence, to maintain superiority in the overall quality of an egg, evaluation of external and internal quality traits has became essential in today's production market. The major egg 
consumption comprises of eggs either laid by exotic or indigenous breed chickens. Eggs from exotic breed are comparatively cheaper in price and high consumption rate when compared with the eggs from indigenous breed. The quality of egg and stability of contents during storage are largely determined by their physical structure and chemical composition. (Hussain et al., 2013) Egg quality in general defines both internal and external quality of egg. External quality is determined based on shell cleanliness, soundness, texture, color and shape. Whereas, internal quality refers to thickness of albumen, firmness of yolk, size of air cell and presence blood spots (Zeidler, 2002).

Hence, the present investigation was carried out to analyze the internal and external quality traits of exotic and indigenous breed eggs.

\section{Materials and Methods}

The fresh ' $A$ ' grade quality eggs of Exotic (White leg horn) and Indigenous breed (Aseel) hens were procured from Sri Sai poultry farm, Raichur (Karnataka).

\section{External quality traits}

The weight of individual eggs obtained from exotic (white leg horn) and indigenous (aseel) breed were measured using an electronic balance (Wensar, DAB220, Chennai, India) having an accuracy of $\pm 0.001 \mathrm{~g}$. The length and width of fresh eggs were measured by digital Vernier calipers (Mitutoyo corporation, CD-6BS, Japan). Shape index describes the ratio of maximum width to length of egg. The shape index of normal egg ranges from70-74 and it is calculated as follows,

Shape index of egg $(\%)=($ Egg width/Egg length) x 100 .

To measure the weight of shell, the eggs of two breeds were broken and egg contents were separated from shell. The inner shell membrane was removed from shells with the help of cotton and kept dry in the open air for 24 h (Hussain et al., 2013). Shell thickness of the eggs of two breeds were determined by measuring the thickness of four pieces of shells, one each from the broad and narrow ends and other two from body of the egg shell were measured with the help of screw gauge having an accuracy of $0.01 \mathrm{~mm}$ (Veena et al., 2015). Shell ratio was determined on the basis of shell weight and egg weight. The shell weight was divided by egg weight to get the shell ratio.

The volume (V) of egg was calculated based on egg weight (Iqbal et al., 2012). For the determination of volume of egg the following formula was used

$\mathrm{V}=0.913 \mathrm{~W}$

Where,

$\mathrm{W}=$ Egg weight $(\mathrm{g})$

The surface area based on length and width of egg was used and expressed in square centimeter in the following equation (Rath et $a l ., 2015)$ for white leg horn. The length and width of egg were estimated using vernier caliper.

Surface area of exotic breed egg (S) was calculated by following formula

$\mathrm{S}=4 \pi \mathrm{r}^{2}$

Where,

$\pi=3.142$

$\mathrm{r}=1 / 4$ (length+breadth)

While surface area of aseel eggs were carried out based on their weight and expressed in following equation (Iqbal et al., 2012). 
Surface area of indigenous breed egg (S) was calculated by following formula

$\mathrm{S}=\mathrm{kW}^{0.67}$

Where,

$\mathrm{k}=4.558$ (constant)

$\mathrm{W}=$ egg weight $(\mathrm{g})$

\section{Internal quality traits}

To measure the internal parameters of eggs obtained from two breeds, the individual eggs were broken on the flat glass plate without disturbing the egg content. The length and width of albumen was determined with the help of digital Vernier caliper. The length and width of yolk was determined with the help of digital Vernier caliper. The height of albumen was measured by placing the penetrometer tip at different locations of thick albumen spread on the glass (Jayanti scientifics; JSI160; India). The height of yolk was measured by placing the penetrometer tip at midpoint of yolk. Albumen weight was calculated as

Albumen weight $=$ Egg weight $-($ Yolk weight + Shell weight).

Yolk weight was calculated as

Yolk weight $=$ Egg weight - (Albumen weight + Shell weight).

The albumen index was estimated by ratio of albumen height to albumen width and multiplied by 100 . The yolk index was estimated by ratio of yolk height to yolk width and multiplied by 100 (Sohail et al., 2013). To measure the albumen ratio, the ratio of albumen weight to total egg weight was taken and values were estimated. To measure the yolk ratio, the ratio of yolk weight to total egg weight were taken (Rath et al., 2015).To determine the yolk diameter of eggs for two breeds, yolk length and breadth were measured. Yolk: Albumen ratio was calculated by ratio of weight of yolk to weight of albumen (Rath et al., 2015). The average values were estimated in percentage.

Haugh unit (Haugh, 1937) is used to determine the quality of egg protein based on the height of egg white and it is calculated by,

$$
\begin{aligned}
& \mathrm{HU}=100 \log \left(\mathrm{H}+7.5-1.7 \mathrm{~W}^{0.37}\right) \\
& \text { Where, } \\
& \mathrm{HU}=\text { Haugh unit } \\
& \mathrm{H}=\text { Height of albumen, } \mathrm{mm} \\
& \mathrm{W}=\text { Egg weight, } \mathrm{g}
\end{aligned}
$$

\section{Results and Discussion}

\section{External quality traits}

The results and discussion of present study i.e, physical properties (external and internal) of exotic and indigenous breed eggs are presented as follows. The mean values of physical (external and internal) characteristics of eggs are summarized in Table 1.

The average values of weight of egg were found to be $55.82 \pm 2.01 \mathrm{~g}$ for exotic breed and $43.66 \pm 2.33 \mathrm{~g}$ indigenous breed eggs, respectively. Significant difference $\left(t_{c a l}>t_{\text {tab }}\right)$ was found between the weights of exotic and indigenous breed eggs, i.e., the weight of egg slightly decreased and this might be due to layer breed. Similar values of $56.60 \mathrm{~g}$ for white leg horn were obtained by Monira $e t$ al., (2003) and Iqbal et al., (2012) reported the similar values of egg weight as $43.10 \mathrm{~g}$ for aseel chicken while evaluating egg geometry of four varieties of indigenous aseel chicken. The mean values of length of egg were found to be $5.52 \pm 0.24 \mathrm{~cm}$ and $5.48 \pm 0.22 \mathrm{~cm}$ for exotic and indigenous breed eggs. The results of length of exotic breed eggs are in good agreement with findings $(5.91 \mathrm{~cm})$ obtained by Monira et al., (2003). Mohan et al., (2000) 
also reported similar results on length $(5.25$ $\mathrm{cm}$ ) of aseel chicken eggs. The change in length may be due to difference in breed and holding period Monira et al., (2003). The average values of width were $3.99 \pm 0.09 \mathrm{~cm}$ and $3.97 \pm 0.09 \mathrm{~cm}$ for exotic and indigenous breed eggs. The results of width are in good agreement with results $(4.21 \mathrm{~cm})$ obtained by Monira et al., (2003) for exotic eggs and Mohan et al., (2000) for width $(3.96 \mathrm{~cm})$ of aseel chicken eggs. It was found no significant difference between length and width of two chicken breeds, respectively.

The mean values of shape index of WLH and aseel eggs were found to be $72.28 \pm 2.07 \%$ and $72.44 \pm 1.25 \%$, respectively. The obtained results are in good relation with the mean values observed by Monira et al., (2003) for shape index $(71.34 \%)$ of WLH eggs. Whereas, shape index of $75.85 \%$ for aseel has been reported earlier by Iqbal et al., (2012). In general, the shape index of 70 to $74 \%$ is considered as normal shape index for commercial layers (Zeidler, 2002). The values above $74 \%$ and below of $70 \%$ lead to cracked and broken eggs (Narushin, 2005). However, results of WLH and aseel eggs in present study are in range of 70 to $74 \%$ indicating no loss of eggs. The surface area values were found to be $67.35 \pm 1.61 \mathrm{~cm}^{2}$ for WLH and $57.29 \pm 2.03 \mathrm{~cm}^{2}$ for aseel eggs, respectively. A non significant difference was found between shape index of exotic and indigenous breed eggs. The results obtained in the present study were on a par with mean values of surface area of WLH eggs $69.90 \mathrm{~cm}^{2}$ determined by Rath et al., (2015). The decrease in the surface area for WLH in present study might be due to decrease in the egg diameter. Similar results of $57.78 \mathrm{~cm}^{2}$ surface area for aseel eggs were reported by Iqbal et al., (2012).

The average values of shell weight were found to be $6.00 \pm 1.12 \mathrm{~g}$ for exotic breed and $5.24 \pm 1.24 \mathrm{~g}$ indigenous breed eggs, respectively. The shell weight reported in this study are in good agreement with Rath et al., (2015) for WLH eggs (6.00 g) and Sohail et al., (2013) for aseel eggs (5.84 g).The shell thickness of exotic breed and indigenous breed eggs were found to be $0.30 \pm 0.05$ and $0.36 \pm 0.06 \mathrm{~cm}$, respectively. Similar results were obtained by Olawumi and Ogunlade (2008) for WLH eggs $0.32 \mathrm{~mm}$ and Sohail et al., (2013) for aseel eggs $0.37 \mathrm{~mm}$, respectively. The mean values of shell ratio were $10.74 \pm 1.63 \%$ and $12.00 \pm 2.18 \%$ for WLH eggs and aseel eggs, respectively. Similar results of $10.42 \%$ were found by Rath et al., (2015) in WLH eggs. Haunshi et al., (2011) analyzed shell ratio of native aseel chicken breeds and results (10\%) found were in good agreement with present study values. The mean values of volume for WLH and aseel eggs were found to be $50.96 \pm 1.83 \mathrm{~cm}^{3}$ and $39.86 \pm 2.13 \mathrm{~cm}^{3}$, respectively. Similarly, Iqbal et al., (2012) reported $39.04 \mathrm{~cm}^{3}$ volume for aseel chicken eggs. It was noted that, results of egg volume obtained in present study are less than egg volume of standard chicken $63.0 \mathrm{~cm}^{3}$ (Zeidler, 2002). This might be due to decrease in weight of eggs.

\section{Internal quality traits}

The mean values of albumen length were found to be $9.28 \pm 0.03 \mathrm{~cm}$ and $7.31 \pm 0.08 \mathrm{~cm}$ for exotic breed eggs and indigenous breed eggs. The average values of yolk length were found to be $4.45 \pm 0.19 \mathrm{~cm}$ and $3.88 \pm 0.37 \mathrm{~cm}$ for exotic breed eggs and indigenous breed eggs. The estimated values of albumen length $(9.20 \mathrm{~cm})$ and yolk length $(4.9 \mathrm{~cm})$ were in good agreement with the findings of Rath et al., (2015) in chicken eggs. No significant difference was found between albumen length and yolk length of exotic and indigenous breeds.

The mean values of albumen width were found to be $6.43 \pm 0.02 \mathrm{~cm}$ for exotic breed eggs and $5.89 \pm 0.10 \mathrm{~cm}$ for indigenous breed eggs, respectively. The average values of yolk 
width were found to be $4.13 \pm 0.02 \mathrm{~cm}$ for exotic breed eggs and $3.73 \pm 0.16 \mathrm{~cm}$ for indigenous breed eggs. Similarly, albumen and yolk width results of present study are close to results $(6.83 \mathrm{~cm}$ and $3.84 \mathrm{~cm})$ found by Olawumi and Ogunlade (2008). It was found significant difference in albumen width of exotic and indigenous breed eggs. The width of albumen was high for WLH compared to aseel and this might be due to increase in weight of albumen in WLH than in the aseel chicken eggs. The average values of albumen height were found to be $7.56 \pm 0.28$ $\mathrm{mm}$ and $5.32 \pm 0.32 \mathrm{~mm}$ for exotic breed eggs indigenous breed eggs.

Table.1 Physical properties of exotic and indigenous breed eggs

\begin{tabular}{|c|c|c|c|c|c|c|c|c|}
\hline \multirow[t]{2}{*}{ SI. No. } & \multirow[t]{2}{*}{ Physical properties } & \multicolumn{3}{|c|}{ Exotic breed eggs } & \multicolumn{3}{|c|}{ Indigenous breed eggs } & \multirow{2}{*}{$\begin{array}{c}\mathbf{t}_{\text {cal }} \\
\text { value }\end{array}$} \\
\hline & & Average & SD & CV & Average & SD & $\mathrm{CV}$ & \\
\hline 1 & Weight $(\mathrm{g})$ & 55.82 & 2.01 & 0.03 & 43.66 & 2.33 & 0.05 & 6.87 \\
\hline 2 & Length $(\mathrm{cm})$ & 5.52 & 0.24 & 0.04 & 5.48 & 0.22 & 0.04 & 0.21 \\
\hline 3 & Width $(\mathrm{cm})$ & 3.99 & 0.09 & 0.02 & 3.97 & 0.09 & 0.02 & 0.07 \\
\hline 4 & Shape index $(\%)$ & 72.28 & 2.07 & 0.02 & 72.44 & 1.25 & 0.01 & 1.48 \\
\hline 5 & Shell weight (g) & 6.00 & 1.12 & 0.18 & 5.24 & 1.24 & 0.23 & 0.80 \\
\hline 6 & Shell thickness (mm) & 0.30 & 0.05 & 0.17 & 0.36 & 0.06 & 0.15 & 1.33 \\
\hline 7 & Shell ratio & 10.74 & 1.63 & 0.15 & 12.00 & 2.18 & 0.18 & 0.80 \\
\hline 8 & Volume $\left(\mathrm{cm}^{3}\right)$ & 50.96 & 1.83 & 0.03 & 39.86 & 2.13 & 0.05 & 6.89 \\
\hline 9 & Surface area $\left(\mathrm{cm}^{2}\right)$ & 67.35 & 1.61 & 0.02 & 57.29 & 2.03 & 0.03 & 6.75 \\
\hline 10 & Albumin length (mm) & 9.28 & 0.03 & 0.004 & 7.31 & 0.08 & 0.01 & 2.43 \\
\hline 11 & Yolk length (mm) & 4.45 & 0.19 & 0.04 & 3.88 & 0.37 & 0.09 & 2.37 \\
\hline 12 & Albumin width (mm) & 6.43 & 0.02 & 0.004 & 5.89 & 0.10 & 0.01 & 9.22 \\
\hline 13 & Yolk width (mm) & 4.13 & 0.02 & 0.006 & 3.73 & 0.16 & 0.04 & 4.34 \\
\hline 14 & Albumin height(mm) & 7.56 & 0.28 & 0.03 & 5.32 & 0.32 & 0.06 & 9.18 \\
\hline 15 & Yolk height (mm) & 16.55 & 0.11 & 0.007 & 14.76 & 0.20 & 0.01 & 13.66 \\
\hline 16 & Albumin weight (g) & 34.17 & 0.52 & 0.01 & 24.46 & 1.37 & 0.05 & 11.55 \\
\hline 17 & Yolk weight (g) & 15.64 & 0.20 & 0.01 & 13.95 & 0.28 & 0.02 & 8.51 \\
\hline 18 & Albumin index (\%) & 9.62 & 0.36 & 0.03 & 8.6 & 0.62 & 0.07 & 2.46 \\
\hline 19 & Yolk index (\%) & 38.72 & 1.33 & 0.03 & 39.43 & 1.65 & 0.04 & 0.58 \\
\hline 20 & Albumin ratio & 61.23 & 0.86 & 0.01 & 56.02 & 0.16 & 0.002 & 10.45 \\
\hline 21 & Yolk ratio & 28.0 & 0.46 & 0.0 & 31.99 & 2.38 & 0.07 & 2.70 \\
\hline 22 & Yolk diameter (mm) & 4.29 & 0.09 & 0.02 & 3.84 & 0.05 & 0.01 & 7.62 \\
\hline 23 & lbumin ratio & 45.78 & 0.14 & 0.003 & 57.14 & 2.50 & 0.07 & 7.88 \\
\hline 24 & Haugh unit & 88.10 & 1.17 & 0.01 & 77.88 & 2.88 & 0.03 & 5.03 \\
\hline
\end{tabular}

SD: Standard deviation; CV: Co-efficient of variation $\mathrm{t}_{4}$ at $1 \%=4.60$ (table value), if $\mathrm{t}_{\mathrm{cal}}>\mathrm{t}_{\mathrm{tab}}$, it is significant.

The mean values of yolk height were found to be $16.55 \pm 0.11 \mathrm{~mm}$ and $14.76 \pm 0.20 \mathrm{~mm}$ for exotic and indigenous breed eggs. Significant difference was found between albumen and yolk heights of both the breed eggs. Veena et al., (2015) evaluated albumen and yolk heights $(7.3$ and $16.70 \mathrm{~mm}$ ) in white leg horns and results found were close to present study. Similar findings $(5.90$ and $15.50 \mathrm{~mm}$ ) were recorded by Sohail et al., (2013) in aseel eggs. 
The average values of albumen weight were found to be $34.17 \pm 0.52 \mathrm{~g}$ and $24.46 \pm 1.37 \mathrm{~g}$ for exotic and indigenous breed eggs. The average values of yolk weight were found to be $15.64 \pm 0.20 \mathrm{~g}$ and $13.95 \pm 0.28 \mathrm{~g}$ for exotic indigenous breed eggs. Significant difference was observed between albumen and yolk weights of exotic and indigenous breed eggs. Exotic breed eggs found to have heavier albumen and yolks than aseel this may be due to effect of breed and strain of selected chickens on quality of eggs due to their genetic variation (Silversiders et al., 2006). The results of present study are in good agreement with the findings (33 $\mathrm{g}$ of albumen and $15 \mathrm{~g}$ of yolk) of Abanikannda and Leigh (2007). The average values of albumen index were found to be $9.62 \pm 0.36 \%$ and $8.60 \pm 0.62 \%$ for exotic and indigenous breed eggs, respectively. The average values of yolk index were found to be $38.72 \pm 1.33 \%$ and $39.43 \pm 1.65 \%$ for exotic and indigenous breed eggs, respectively. No significant difference was found between albumen and yolk indices of exotic and indigenous breed eggs. The results found in current study for albumen index are in close agreement with findings (9.98\% and $40.24 \%$ ) of Rath et al., (2015) for WLH eggs. Similarly, Sohail et al., (2013) recorded yolk index values as $40.02 \%$ in aseel chickens. The average values of albumen ratio were found to be $61.23 \pm 0.86 \%$ and $56.02 \pm 0.16 \%$ for exotic and indigenous breed eggs, respectively. The mean values of yolk ratio were found to be $28.03 \pm 0.46 \%$ and $31.99 \%$ for exotic and indigenous breed eggs, respectively. Similar results of albumen ratio $(57.00 \%)$ and yolk ratio $(31.00 \%)$ were found by Olawumi and Ogunlade (2008) for chicken eggs. The mean values of yolk diameter were $4.29 \pm 0.09 \mathrm{~cm}$ and $3.84 \pm 0.05 \mathrm{~cm}$ for $\mathrm{WLH}$ eggs and aseel eggs, respectively. Significant difference was found between yolk diameters of both the breeds. Similar results of $4.53 \pm 0.09 \mathrm{~cm}$ were found by Rath et al.,
(2015) in chicken eggs. The mean values of yolk: albumen ratio of exotic breed and indigenous breed eggs were found to be $45.78 \pm 0.14$ and $57.17 \pm 0.52 \%$, respectively. Significant difference was found between yolk: albumen ratio of exotic and indigenous breeds. The higher yolk: albumen ratio was observed in aseel breed as compared with WLH due to the fact aseel breed eggs had higher yolk weights. The results of yolk: albumen ratio of white leg horns were close to findings of Rath et al., (2015) in chicken eggs. The mean values of Haugh unit were $88.10 \pm 1.17$ and $77.88 \pm 0.52$ for WLH and aseel eggs, respectively. No significant difference was found between haugh unit of exotic and indigenous breed eggs. The results of present study were on a par with findings (92.00\%) of Rath et al., (2015) in white leg horns and Haunshi et al., (2011) for aseel breed eggs (75.43\%), respectively.

In conclusion, the present study provides data on physical properties of exotic (WLH) and indigenous (aseel) breed eggs. There is no much variation in the length, width, shape index, shell weight, shell thickness and shell ratio between WLH and aseel eggs. The properties like weight, surface area and volume decreased for aseel eggs compared to WLH eggs. However, internal parameters such as albumen length, yolk length, yolk width, albumen index, yolk index, yolk ratio and Haugh unit values have no much variation comparatively. Whereas, the parameters like albumen width, albumen height, yolk height, albumen weight, yolk weight, albumen ratio, yolk diameter and yolk: albumen ratio were decreased for aseel eggs compared to WLH eggs. The results indicate that external and internal quality traits are superior in WLH eggs over aseel eggs. Hence, on overall basis, WLH eggs are considered for commercial usage.

\section{References}


Abanikannda, O. T. F. and Leigh, A. O., 2007, Allometric relationships between composition and size of chicken table eggs. International Journal of Poultry Science, 6(3): 211-217.

Ahmadi, S., Zad, S. S. and Zeinoddin, S. M., 2016, Effect of heat, nisin and ethylene diamine tetra acetate treatments on shelf-life extension of liquid whole egg. International Journal of Food Science and Technology, 51(2): 396-402.

Haugh, R. R., 1937. The Haugh unit for measuring egg quality. United States Egg and Poultry Magazine, 43(4): 522555.

Haunshi, S., Niranjan, M., Shanmugam, M., Padhi, M. K., Reddy, M. R., Sunitha, R., Rajkumar, U. and Panda, A. K., 2011, Characterization of two Indian native chicken breeds for production, egg and semen quality, and welfare traits. Poultry Science, 90(2): 314-320.

Hussain, S., Ahmed, Z., Khan, M.N. and Khan, T.A., 2013, A study on quality traits of chicken eggs collected from different areas of Karachi. Sarhad Journal of Agriculture, 29(2): 255-259.

Iqbal, A., Akram, M., Sahota, A.W., Javed, K., Hussain, J., Sarfraz, Z. and Mehmood, S., 2012, Laying characteristics and egg geometry of four varieties of indigenous Aseel chicken in Pakistan. Journal of Animal and Plant Sciences, 22(4): 848-852.

Mohan, S., Umesh, S. and Gurung, B.S., 2000, Evaluation of egg weight and its various measurement attributes in indigenous Aseel breed of chicken. Indian Journal of Poultry Science, 35(3): 312-314.

Monira, K. N., Salahuddin, M. and Miah, G., 2003, Effect of breed and holding period on egg quality characteristics of chicken. International Journal of Poultry Science, 2(4): 261-263.

Mutayoba, S. K., Dierenfeld, E., Mercedes,
V. A., Frances, Y. and Knight, C. D., 2011, Determination of chemical composition and anti-nutritive components for Tanzanian locally available poultry feed ingredients. International Journal of Poultry Science, 10(5): 350-357.

Narushin, V. G., 2005, Egg geometry calculation using the measurements of length and breadth. Poultry science, 84(3): 482-484.

Olawumi, S. O. and Ogunlade, J. T., 2008, Phenotypic correlations between some external and internal egg quality traits in the exotic Isa Brown layer breeders. Asian Journal of Poultry Science, 2(1): 30-35.

Rath, P. K., Mishra, P. K., Mallick, B. K. and Behura, N. C., 2015, Evaluation of different egg quality traits and interpretation of their mode of inheritance in white leg horns. Veterinary World, 8(4): 449-454.

Silversides, F. G., Korver, D. R. and Budgell, K. L., 2006, Effect of strain of layer and age at photostimulation on egg production, egg quality, and bone strength. Poultry Science, 85(7): 11361144.

Sohail, A., Muhammad, A., Hussain, J., Iqbal, A., Usman, M., Rehman, A. and Hussnain, F., 2013, Comparative study on production performance, egg quality, egg geometry and hatching traits of three age groups of indigenous Peshawari Aseel chicken. Journal of Animal Veterinary advances, 2(2): 2125.

Stadelman, W.J., 1995, The preservation of quality in shell eggs. Egg science and technology, 4(2): 67-79.

Veena, D., Eswara Rao, B., Mallika, N. E. and Azad, S. A. K., 2015, A study on quality traits of chicken eggs collected in and around gannavaram, Krishna district in different seasons. 
International Journal of Recent Scientific Research, 6(9): 6487-6489

www.faostat.com

www.indiastat.com

www.usda.gov
Zeidler, G., 2002, Shell egg quality and preservation. In commercial chicken meat and egg production. pp. 11991217, Springer, Boston, USA.

\section{How to cite this article:}

Sumashree, N., Sharanagouda Hiregoudar, Udaykumar Nidoni, K.T. Ramappa, Nagaraj Naik and Vasanth Kumar, G.D. 2019. Study on Physical Properties of Exotic and Indigenous breed Eggs. Int.J.Curr.Microbiol.App.Sci. 8(09): 327-334.

doi: https://doi.org/10.20546/ijcmas.2019.809.039 